\title{
Conhecimentos Necessários à Docência no Âmbito do PIBID/Matemática no Brasil
}

\author{
Knowledge Needed for Teaching in the Scope of PIBID/Mathematics in Brasil
}

\author{
Márcio Urel Rodrigues*a Rosana Giaretta Sguerra Miskulin ${ }^{\mathrm{b}}$; Luciano Duarte da Silva ${ }^{\mathrm{c}}$ \\ ${ }^{a}$ Universidade do Estado de Mato Grosso. MT, Brasil.

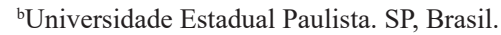 \\ 'Instituto Federal de Educação Ciências e Tecnologia. GO, Brasil. \\ *E-mail: marcio.rodrigues@unemat.br
}

\begin{abstract}
Resumo
Neste artigo queremos encontrar respostas à questão norteadora: Quais são os conhecimentos necessários à docência evidenciados pelos participantes do PIBID/Matemática no Brasil? objetivamos explicitar os conhecimentos necessários à docência presentes na formação inicial de professores de Matemática na perspectiva dos participantes do PIBID/Matemática no Brasil. Utilizamos como fundamentação teórica os "Conhecimentos necessários à Docência", apresentados por Shulman. Para atender a esse objetivo, realizamos um recorte em uma pesquisa de doutorado defendida na UNESP - Rio Claro/SP. Os dados foram constituídos por meio de Questionários respondidos por 394 participantes dos subprojetos do PIBID/Matemática de 83 universidades do Brasil. Os dados foram analisados por meio da Análise de Conteúdo, os quais nos conduziram à identificação de que a participação nas atividades do PIBID/Matemática proporcionou oportunidades para os licenciandos em Matemática adquirirem os sete conhecimentos necessários para a atuação docente. Além disso, identificamos um oitavo conhecimento necessário à docência - os Conhecimentos Políticos da Profissão -, que envolve a necessidade dos futuros professores conhecerem dimensões importantes do trabalho docente, como gestão escolar e movimento sindical, para enfrentar os diversos desafios da profissão docente. Constatamos ainda que o PIBID apresentou possíveis caminhos para melhorar os processos formativos de professores de Matemática no Brasil, pois proporcionou aos licenciandos em Matemática oportunidades de adquirirem os conhecimentos necessários à docência de um professor de Matemática.
\end{abstract}

Palavras-chave: Conhecimentos Necessários à Docência. PIBID. Formação Inicial de Professores de Matemática.

\begin{abstract}
In this article we want to find answers to the guiding question: What are the necessary knowledge for teaching evidenced by the participants of PIBID / Mathematics in Brazil? We aim make explicit the Knowledge Needed for Teaching present in the initial formation of Mathematics teachers from the perspective of PIBID/Mathematics participants in Brazil. We use as theoretical foundation the "Knowledge Needed to Teachers" presented by Shulman. To meet this objective, we made a cut of a doctoral research defended at UNESP - Rio Claro/SP. The data were composed by questionnaires answered by 394 participants of the PIBID/Mathematics' subprojects of 83 universities of Brazil. The data were analyzed by Content Analysis, which led us to identify that participation in the activities of PIBID/Mathematics provided opportunities for Mathematics graduates to acquire the seven Knowledge Needed to Teachers. In addition, we identified an eighth knowledge necessary for teaching - the Political Knowledge of the Profession -, which involves the need for future teachers to know important dimensions of teaching, such as school management and trade union movement, to address the various challenges of the teaching profession. We also found that PIBID presented possible ways to improve the training processes of mathematics teachers in Brazil, as it provided mathematics graduates with opportunities to acquire the knowledge needed to teach a mathematics teacher.
\end{abstract}

Keywords: Knowledge Needed for Teaching. Initial Teacher Training in Mathematics. PIBID.

\section{Introdução}

Apresentamos no presente artigo um recorte da tese de doutorado defendida pelo primeiro autor e orientada pela segunda autora no Programa de Pós-Graduação em Educação Matemática na Universidade Estadual Paulista "Júlio de Mesquita Filho" (Unesp) - Rio Claro/SP. O referido recorte envolve os conhecimentos necessários à docência presentes na formação inicial de professores de Matemática no âmbito do PIBID/Matemática no Brasil.

Trazemos algumas reflexões suscitadas pela análise dos dados da referida pesquisa envolvendo o Programa Institucional de Bolsa de Iniciação à Docência (PIBID). Dessa maneira, esperamos que os dados apresentados e discutidos no presente artigo contribuam como aporte teórico-metodológico para estudos na área da Educação Matemática.

O PIBID é um programa que oferece bolsas para que os licenciandos exerçam atividades pedagógicas em escolas públicas de Educação Básica, contribuindo para "a integração entre teoria e prática, para a aproximação entre universidades e escolas e para a melhoria de qualidade da educação brasileira". Assim, o PIBID é concebido como sendo "um programa de incentivo e valorização do magistério e de aprimoramento do processo de formação de docentes para a educação básica" (Capes, 2014, p. 67).

No PIBID, os Licenciandos bolsistas são orientados por Coordenadores de área (professores das licenciaturas das IES) e por Supervisores (professores em serviço das escolas 
públicas), pois o diálogo e a interação entre Licenciandos, Coordenadores e Supervisores geram um movimento dinâmico e virtuoso de formação recíproca e crescimento contínuo (Capes, 2014).

A partir do exposto, queremos encontrar respostas à questão norteadora: Quais são os conhecimentos necessários à docência evidenciados pelos participantes do PIBID/ Matemática no Brasil? Assim, no presente texto, objetivamos explicitar os conhecimentos necessários à docência presentes na formação inicial de professores de Matemática na perspectiva dos participantes do PIBID/Matemática no Brasil.

Para alcançarmos esse objetivo, no presente texto, em um primeiro momento, apresentamos nossa fundamentação teórica envolvendo a base de conhecimento da docência proposta por Shulman (1986, 1987, 2005). Logo após, elencamos os procedimentos metodológicos utilizados para coletar e analisar os dados com os participantes do PIBID/ Matemática no Brasil.

A seguir, realizamos um movimento dialógico para descrever a análise interpretativa dos dados. Explicitamos ainda algumas reflexões suscitadas pela análise dos dados referentes à maneira como são explorados os conhecimentos necessários à docência no desenvolvimento das atividades do PIBID/Matemática no Brasil.

\section{Fundamentação Teórica: Conhecimentos Necessários à Docência}

Entre os diferentes modos de entender o que um professor precisa saber para poder ser professor e exercer sua profissão, assumimos que a perspectiva teórica dos conhecimentos necessários à docência (Shulman, 1986, 1987, 2005) sustenta o processo de formação inicial dos cursos de licenciatura desenvolvidos no Brasil.

Shulman (1987, p. 106) explicita que a base de conhecimentos para o ensino "é o corpo de entendimentos, conhecimentos, habilidades e disposições de que um professor precisa para atuar efetivamente numa dada situação de ensino". O referido autor utiliza o termo "conhecimento" para fazer referência àquilo que os professores deveriam compreender sobre a docência, para favorecer um processo de ensino-aprendizagem eficiente.

Em outro momento, o autor afirma que os conhecimentos necessários à docência são os conhecimentos que os "professores deveriam saber, fazer, compreender ou professar para converter o ensino em algo mais que uma forma de trabalho individual e para que seja considerada entre as profissões prestigiadas" (Shulman, 2005, p.5). O referido autor elaborou uma base de conhecimento da docência composta pelas seguintes categorias:

1) conhecimento do conteúdo; 2) conhecimento pedagógico - conhecimento didático geral; 3) conhecimento pedagógico do conteúdo; 4) conhecimento do currículo; 5) conhecimento dos alunos e da aprendizagem; 6) conhecimento dos contextos educativos; 7) conhecimento dos objetivos, das finalidades e dos valores educativos (Shulman, 2005, p. 11).

Na nossa visão, a base de conhecimentos necessários à docência deveria ser considerada pelos cursos de Licenciatura em Matemática no Brasil, pois, conforme explicita Silva (2015, p.205), as características e objetivos dos cursos de Licenciatura em Matemática são diferentes dos cursos de Bacharelado em Matemática, pois: "a Licenciatura em Matemática possui como foco formar professores e pesquisadores na área de Educação Matemática para a atuação na Educação Básica, enquanto o Bacharelado em Matemática possui como foco: formar pesquisadores na área da Matemática".

Para nós, os cursos de Licenciatura em Matemática deveriam possuir uma identidade curricular, ou seja, o currículo para formar um professor de Matemática deveria ser pensado e colocado em prática desde o primeiro ano da Licenciatura. Assim sendo, acreditamos que estaríamos preparando os futuros professores de Matemática com uma visão mais humanista, crítica e democrática para o ensino da Matemática nas escolas da Educação Básica, e não simplesmente priorizando as disciplinas de conteúdo específico de Matemática.

A esse respeito, Lins (2000, p. 26) enfatiza que as disciplinas específicas de conteúdo de Matemática na formação de professores precisam passar por uma reformulação substancial, pois "as licenciaturas em Matemática necessitam assumir decididamente uma vocação de formar professores ao invés de formar semi-bacharéis que são semi-educadores".

Com base no referencial explicitado, acreditamos que, na formação inicial de professores de Matemática, precisamos com urgência ultrapassar a visão equivocada de que basta dominar os conteúdos de Matemática para um professor desenvolver uma boa aula de Matemática nas escolas da Educação Básica.

\section{Material e Métodos}

Visando delinear compreensões a respeito do objetivo do presente artigo - explicitar os conhecimentos necessários à docência presentes na formação inicial de professores de Matemática na perspectiva dos participantes do PIBID/ Matemática no Brasil -, utilizamos a pesquisa qualitativa, por visar descrever e interpretar a perspectiva dos participantes em relação ao objeto investigado, conforme explicitado por D’Ambrosio (2004, p. 18): “as pesquisas qualitativas referemse às pessoas e às suas ideias, procurando dar sentido aos seus discursos".

Os participantes da pesquisa atuavam como bolsistas do Programa Institucional de Bolsa de Iniciação à Docência (PIBID). O referido programa oferece bolsas para que alunos de licenciatura exerçam atividades pedagógicas em escolas públicas de Educação Básica, contribuindo para "a integração entre teoria e prática, para a aproximação entre universidades e escolas e para a melhoria de qualidade da educação brasileira" (Capes, 2014, p. 67). 
No PIBID, os licenciandos bolsistas são orientados por coordenadores de área (professores dos cursos de licenciatura das IES) e por supervisores (professores em serviço das escolas públicas). Assim sendo, para coletar os dados da pesquisa, utilizamos Questionários que foram elaborados utilizando os formulários do Google Docs e enviados on-line para os participantes.

Responderam aos Questionários Qualitativos ou Objetivos 394 participantes do PIBID/Matemática, sendo que: 129 participantes responderam ao Questionário Qualitativo com dez perguntas abertas (subjetivas); e 265 participantes responderam ao Questionário Objetivo com questões de natureza fechada - questões de múltipla escolha. Os participantes estavam vinculados a 83 universidades, de um total de 195 vinculadas ao PIBID em 2013.

Para analisar os dados, utilizamos alguns conceitos da Análise de Conteúdo na perspectiva elucidada por Bardin (1977, p. 42), que a define como sendo um conjunto de técnicas de análise das comunicações com o objetivo de "obter, por procedimentos objetivos e sistemáticos de descrição do conteúdo das mensagens, indicadores que permitam a inferência de conhecimentos relativos às condições de produção/recepção destas mensagens".

Considerando esse referencial metodológico, apresentamos, na Figura 1, a dinamicidade do design metodológico da pesquisa desenvolvida segundo alguns conceitos da Análise do Conteúdo na perspectiva da Bardin (1977).

Figura 1 - Design Metodológico da Análise de Conteúdo Bardin (1977).

Fonte: Os Autores.

Com base na Figura 1, apresentada acima, explicitamos a compreensão dos conceitos da Análise de Conteúdo na perspectiva da Bardin (1977).

A Leitura Flutuante tem por objetivo identificar os aspectos que "saltam aos olhos" do pesquisador em relação ao corpus da pesquisa, pois, para Bardin (1977, p. 96), a Leitura Flutuante "consiste em estabelecer o contato do pesquisador com os documentos da coleta de dados, momento em que se começa a conhecer o texto, deixando-se invadir por impressões e orientações".

As Unidades de Contexto são concebidas como sendo partes ou trechos significativos das respostas ou depoimentos que conduzem à identificação das Unidades de Registro, pois, segundo Bardin (1977, p. 107), uma "Unidade de Contexto corresponde ao segmento da mensagem, cujas dimensões (superiores às da Unidade de Registro) são ótimas para que se possa compreender o significado exato da Unidade de Registro".

As Unidades de Registro são constituídas das Unidades de Contexto e são concebidas por Bardin (1977, p. 104) como sendo "uma unidade de significação a codificar e corresponde ao segmento de conteúdo a considerar como unidade de base, visando à categorização". No presente artigo, utilizamos o tema como a Unidade de Registro para desvendar os "núcleos de sentido" (Bardin, 1977, p. 105) das comunicações contidas nas respostas dos participantes aos Questionários, pois realizamos um movimento de idas e vindas buscando extrair os "núcleos de sentido" dos excertos dos dados.

Os Eixos Temáticos são provenientes das articulações entre as Unidades de Registro. Rodrigues (2016, p.105), com base em Bardin (197), afirma que essas articulações acontecem "por meio de um procedimento minucioso de interpretação das similaridades, confluências e divergências. Logo após, os Eixos Temáticos são articulados entre si para a constituição das Categorias de Análise da pesquisa”.

Para Bardin (1977, p.153), “as Categorias de Análise são configuradas conforme os temas que emergem do texto, num processo de classificação dos elementos com características semelhantes, permitindo seu agrupamento". Já a Interpretação das Categorias de Análise é o momento da intuição, da análise reflexiva e crítica do pesquisador, pois ele realiza suas interpretações de acordo com o quadro teórico e os objetivos propostos.

A análise dos dados realizada por meio desses conceitos da Análise de Conteúdo - Bardin (1977) nos conduziu à constituição de uma Categoria de Análise denominada Formação e Profissionalização Docente. Assim sendo, apresentamos no Quadro 1 um detalhamento do movimento utilizado da Análise de Conteúdo na constituição da referida Categoria de Análise.

Quadro 1 - Procedimento para a constituição da Categoria de Análise

\begin{tabular}{|c|c|c|}
\hline Unidades de Registro & Eixos Temáticos & $\begin{array}{c}\text { Categorias de } \\
\text { Análise }\end{array}$ \\
\hline $\begin{array}{l}\text { Conhecimento da prática } \\
\text { docente } \\
\text { Conhecimento } \\
\text { dos conteúdos de } \\
\text { Matemática }\end{array}$ & \multirow{3}{*}{$\begin{array}{l}\text { Conhecimentos } \\
\text { necessários à } \\
\text { Docência }\end{array}$} & \multirow{4}{*}{$\begin{array}{c}\text { Formação e } \\
\text { Profissionalização } \\
\text { Docente }\end{array}$} \\
\hline $\begin{array}{l}\text { Conhecimento } \\
\text { pedagógico do conteúdo } \\
\text { Conhecimento político } \\
\text { da profissão }\end{array}$ & & \\
\hline $\begin{array}{l}\text { Abordagens } \\
\text { metodológicas no PIBID } \\
\text { Recursos e materiais } \\
\text { didáticos }\end{array}$ & & \\
\hline \begin{tabular}{|l|}
$\begin{array}{l}\text { Atratividade da carreira } \\
\text { docente }\end{array}$ \\
Excesso de atividades do \\
professor \\
Carreira docente \\
\end{tabular} & $\begin{array}{c}\text { Profissionalização } \\
\text { Docente }\end{array}$ & \\
\hline
\end{tabular}

Fonte: Os Autores.

A partir das articulações entre as Unidades de Registro, 
Eixos Temáticos e Categoria de Análise, explicitados no Quadro 1, no presente artigo, realizamos o movimento dialógico do Eixo Temático "conhecimentos necessários à docência". Assim sendo, apresentamos, a seguir, alguns excertos que serão interpretados por meio de um movimento dialógico com os referenciais teóricos, para elencarmos os conhecimentos necessários à docência dos futuros professores de Matemática.

\section{Movimento Dialógico - Análise Interpretativa dos Dados}

Neste item, realizamos um movimento dialógico envolvendo o Eixo Temático conhecimentos necessários à docência, que foi constituído pelas Unidades de Registro: (i) conhecimento da prática docente; (ii) conhecimento dos conteúdos de matemática; (iii) conhecimento pedagógico do conteúdo; (iv) conhecimento político da profissão; (v) abordagens metodológicas no PIBID; (vi) Recursos e materiais didáticos.

O movimento dialógico envolvendo as nossas constatações que se mostraram recorrentes nos dados provenientes dos questionários e entrevistas com o referencial teórico que nos auxiliaram na compreensão dos conhecimentos necessários à docência presentes na formação inicial de professores de Matemática na perspectiva dos participantes do PIBID/ Matemática no Brasil. Ressaltamos que para cada uma das constatações, apresentamos alguns excertos das respostas e depoimentos dos participantes para corroborar com a nossa constatação.

Respaldamo-nos teoricamente em Shulman (1986, 1987, 2005), para discutir os aspectos envolvendo os conhecimentos necessários à docência, pois o referido autor utiliza o termo "conhecimento" para fazer referência àquilo que os professores deveriam compreender sobre a docência, para favorecer um processo de ensino-aprendizagem eficiente.

Os conhecimentos necessários à docência são explicitados por Shulman (2005), que elaborou uma base de conhecimento da docência composta por sete tipos de conhecimentos (Figura 2).

Figura 2 - Conhecimentos necessários à docência

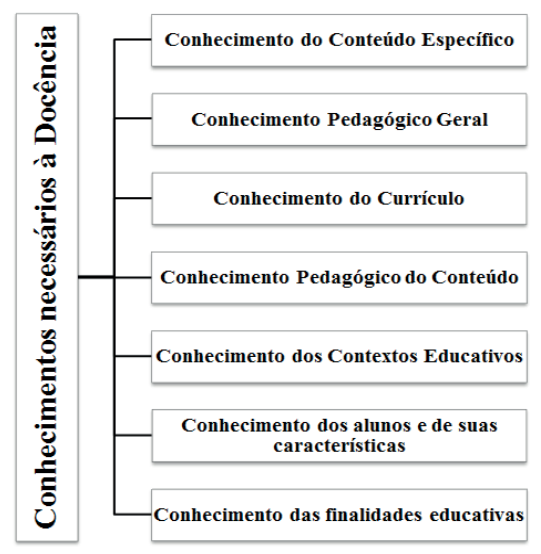

Fonte: Adaptada de Shulman (2005).
Com base nas categorias elaboradas por Shulman (2005), apresentamos, a seguir, a maneira como esses conhecimentos foram explorados e adquiridos pelos licenciandos em Matemática no desenvolvimento das atividades do PIBID/ Matemática no Brasil.

Apresentamos algumas constatações evidenciadas por meio dos aspectos que se mostraram recorrentes nos dados e também referenciais que nos auxiliaram na compreensão dos conhecimentos necessários à docência presentes na formação inicial de professores de Matemática na perspectiva dos participantes do PIBID/Matemática no Brasil

Um primeiro conhecimento necessário à docência, constatado nos excertos dos participantes do PIBID/ Matemática, relaciona-se ao conhecimento dos conteúdos específicos.

Reflexão crítica e ampla sobre conteúdos matemáticos da Educação Básica (F1).

Conscientizar sobre a importância do domínio dos conteúdos matemáticos para os alunos (S1).

Aprendi a prezar pela qualidade dos conteúdos e não apenas a quantidade (L16)

Maior conhecimento de todos os conteúdos específicos para atuar na prática educativa (L63).

Conforme sinalizam esses excertos, compreendemos que as atividades do PIBID têm proporcionado oportunidades para os licenciandos em Matemática estudarem e aprenderem ou aperfeiçoarem os conteúdos matemáticos que utilizarão na prática docente, pois um bom professor precisa em primeiro lugar ter um domínio conceitual dos conteúdos destinados à Educação Básica.

Para Shulman (1986), o conhecimento do conteúdo específico - em nosso caso, os conteúdos de Matemática - refere-se ao conhecimento do professor a respeito do conteúdo que ensina, isto é, o professor deve possuir um amplo conhecimento dos conteúdos relativos à Matemática. Para nós, os licenciandos em Matemática precisam adquirir conhecimentos de conteúdo matemático para ensinar com consistência, pois o domínio desses conhecimentos amplia as possibilidades de intervenção docente, e a sua deficiência limita o que eles terão que ensinar futuramente para os seus futuros alunos.

Nesse sentido, a SBEM (2003, p.2) explicita que o “domínio dos conteúdos matemáticos é fundamental para o desenvolvimento de competências profissionais para a docência na Educação Básica". Compactuamos com o referido documento, pois também entendemos que o domínio conceitual dos conteúdos é fundamental para a atuação profissional dos professores de Matemática, no entanto, na nossa visão, não é o único, e nem o mais importante, pois existem outros conhecimentos relevantes e que precisam ser considerados pelos futuros professores de Matemática para atuar nas escolas da Educação Básica.

Para nós, a formação acadêmica (domínio dos conteúdos de Matemática) desenvolvida nas disciplinas específicas nas licenciaturas em Matemática é essencial para a prática 
de qualquer professor de Matemática. No entanto, a supervalorização dessa formação específica, em detrimento de outros conhecimentos necessários, é, a nosso ver, um aspecto preocupante, se considerarmos que o licenciando em Matemática atuará na Educação Básica.

Um segundo conhecimento necessário à docência, identificado nos excertos dos participantes do PIBID/ Matemática, relaciona-se ao conhecimento pedagógico ou didático geral, o qual é concebido por Shulman (1987) como sendo o conhecimento que envolve os princípios ou estratégias de gestão e organização de classe, úteis para ensinar o conteúdo. Para ele, o conhecimento pedagógico transcende o âmbito de uma disciplina, pois não são conhecimentos específicos destinados a uma matéria ou disciplina e, sim, algo mais abrangente e geral, que procura alcançar objetivos mais amplos com o seu ensino para a formação dos alunos.

Os conhecimentos pedagógicos que os futuros professores precisam adquirir estão relacionados à organização do trabalho docente nas escolas. Assim sendo, explicitamos quatro aspectos envolvendo o referido conhecimento (Quadro 2).

Quadro 2 - Aspectos do Conhecimento pedagógico geral

\begin{tabular}{|c|c|}
\hline $\begin{array}{c}\text { Conhecimento } \\
\text { Pedagógico } \\
\text { Geral }\end{array}$ & $\begin{array}{c}\text { Excertos Relacionados aos Aspectos do } \\
\text { Conhecimento Pedagógico ou Didático } \\
\text { Geral }\end{array}$ \\
\hline $\begin{array}{l}\text { Aprimoramento } \\
\text { dos } \\
\text { conhecimentos } \\
\text { para aperfeiçoar } \\
\text { as práticas } \\
\text { pedagógicas em } \\
\text { sala de aula }\end{array}$ & $\begin{array}{l}\text { Acredito que conseguimos aprimorar em } \\
\text { todos nós diferentes conhecimentos, na } \\
\text { partilha de experiências (F1). } \\
\text { O PIBID é um ótimo programa, pois } \\
\text { através dele podemos aperfeiçoar nossos } \\
\text { conhecimentos com relação a práticas } \\
\text { pedagógicas (L57). } \\
\text { Vamos aprendendo que temos que estar } \\
\text { sempre nos readaptando e aperfeiçoando } \\
\text { (L70). } \\
\text { Com o PIBID temos a oportunidade de } \\
\text { aperfeiçoar, ou seja, aprender na prática, } \\
\text { o que a Universidade não tem como nos } \\
\text { proporcionar por si só (L73). }\end{array}$ \\
\hline $\begin{array}{l}\text { Visão realista } \\
\text { da sala de aula } \\
\text { e da prática } \\
\text { docente }\end{array}$ & $\begin{array}{l}\text { O PIBID proporciona aos acadêmicos uma } \\
\text { visão real de como é uma sala de aula (L7). } \\
\text { Foram muitos os aprendizados relacionados } \\
\text { à prática docência, mas acredito que as } \\
\text { discussões me ajudaram a compor uma ideia } \\
\text { mais realista da profissão (L55). } \\
\text { No PIBID, os acadêmicos têm a possibilidade } \\
\text { de conhecer a realidade da escola pública } \\
\text { (S22). }\end{array}$ \\
\hline $\begin{array}{c}\text { Aspectos } \\
\text { Pedagógicos }\end{array}$ & $\begin{array}{l}\text { Aprendemos a lidar com a rotina de uma } \\
\text { escola, vamos desenvolvendo técnicas para } \\
\text { conquistar os alunos, aprendemos como nos } \\
\text { posicionar diante de determinadas situações, } \\
\text { experimentamos didáticas, refletimos sobre o } \\
\text { porquê de cada erro e cada acerto (L12). } \\
\text { Experiência na área de docente, ter uma boa } \\
\text { didática, falar em público (L3). } \\
\text { Os aspectos didáticos que mais contribuíram } \\
\text { foram: domínio de turma, afetividade com os } \\
\text { alunos, o contexto social do aluno, além do } \\
\text { tempo de aprendizagem de cada educando } \\
\text { (S12). }\end{array}$ \\
\hline
\end{tabular}

\begin{tabular}{|c|l|}
\hline & $\begin{array}{l}\text { O PIBID proporcionou ampliar os } \\
\text { conhecimentos da prática de ensino de } \\
\text { Matemática (F13). } \\
\text { Cada dia é um aprendizado, um tijolinho no } \\
\text { Aprendizagem } \\
\text { da prática } \\
\text { muro da aprendizagem da docência (F20). } \\
\text { No PIBID estou aprendendo a ser um docente } \\
\text { que possa contribuir para a sociedade (L22). } \\
\text { Estou tendo experiências fantásticas } \\
\text { relacionadas ao mundo da Matemática. São } \\
\text { vivências positivas, pois é realmente uma } \\
\text { preparação à docência (L63). }\end{array}$ \\
\hline
\end{tabular}

Fonte: Dados da pesquisa.

Em relação ao aprimoramento dos conhecimentos para aperfeiçoar as práticas pedagógicas em sala de aula adquiridos pelos participantes do PIBID/Matemática, compreendemos que as experiências envolvendo as práticas pedagógicas nas salas de aula contribuem para que os futuros professores de Matemática não assumam uma sala de aula somente com conhecimentos teóricos repassados pelos formadores de seus cursos de licenciatura, mas também com a experiência como docente em sala de aula nas escolas. Nesse sentido, identificamos que as experiências vivenciadas no PIBID pelos licenciandos em Matemática em sala de aula proporcionaram condições para eles adquirirem aspectos do conhecimento didático geral.

Em relação à visão realista da sala de aula e da prática docente adquirida pelos participantes do PIBID/Matemática, identificamos que, além do contato e da inserção nas escolas, o PIBID tem proporcionando aos licenciandos em Matemática um conhecimento realista da prática docente nas escolas públicas, por meio da vivência em diversas atividades formativas.

Complementando essas ideias, apresentamos as respostas dos 174 licenciandos em Matemática a uma questão em relação à atividade docente (Quadro 3).

Quadro 3 - Visão dos licenciandos em Matemática sobre a atividade docente.

\begin{tabular}{|c|c|c|}
\hline $\begin{array}{c}\text { Sua participação no PIBID/Matemática } \\
\text { ampliou suas visões sobre a atividade } \\
\text { docente? }\end{array}$ & F & $\mathbf{( \% )}$ \\
\hline Sim & 173 & $99,4 \%$ \\
\hline Não & 01 & $0,6 \%$ \\
\hline
\end{tabular}

Fonte: Dados da Pesquisa.

Com esses dados, podemos inferir que o PIBID ampliou a visão dos licenciandos em Matemática sobre a atividade docente. Assim, podemos inferir que a vivência no ambiente escolar proporcionada pelo PIBID/Matemática contribuiu para que os licenciandos conhecessem mais profundamente o possível futuro local e ambiente de trabalho.

Em relação aos aspectos pedagógicos adquiridos pelos participantes do PIBID/Matemática, notamos que o domínio de uma sala de aula é um fator importante na organização do trabalho docente nas escolas e se enquadra como um dos aspectos pedagógicos. Em relação ao domínio da sala durante a atuação dos licenciandos nas escolas, os supervisores 
procuravam acompanhá-los e auxiliá-los nos momentos de planejamento e desenvolvimento das intervenções didáticas.

Em relação à aprendizagem da prática docente adquirida pelos participantes do PIBID/Matemática, podemos dizer que a atuação dos licenciandos em Matemática no contexto escolar proporcionou oportunidades para eles aprenderem diversas dimensões da prática docente, pois é na escola que os conhecimentos relacionados à prática docente podem ser desenvolvidos e aprimorados.

Um terceiro conhecimento necessário à docência identificado nos excertos dos participantes do PIBID/ Matemática relaciona-se ao conhecimento pedagógico do conteúdo, o qual é definido por Shulman (1986, p. 9) como sendo aquele conhecimento "que vai além do conhecimento da matéria em si e chega à dimensão do conhecimento da matéria para o ensino".

Reflexão crítica e ampla das diferentes metodologias de ensino da Matemática (F1).

Realizávamos leituras de temas da Educação Matemática, Modelagem Matemática e outras. Os licenciandos discutiam e buscavam outras metodologias de ensino (F5).

Os licenciandos entenderam que a forma de apresentar o conteúdo faz diferença. Assim, eles elaboravam atividades lúdicas, investigativas, com conteúdos matemáticos (F20).

Com as atividades propostas, tive a oportunidade de compartilhar experiências com os licenciandos, aprendendo metodologias inovadoras que na maioria das vezes não temos tempo de pesquisar e em troca compartilha com o bolsista (S1).

A oportunidade de ver e rever conceitos e metodologias de ensino e aprendizagem, bem como a melhora da dinâmica na sala de aula (S2).

$\mathrm{Eu}$ acho que as universidades deveriam criar uma cadeira apenas com prática de ensino voltada só para jogos educativos, pois percebi que, quando os bolsistas levavam para a sala os jogos, todos os alunos se entregavam de corpo e alma para desenvolver os obstáculos que os jogos lhes ofereciam (S9).

O PIBID prende mais a atenção dos alunos, porque desenvolvemos atividades diferenciadas. Os alunos demonstram mais interesse pelas aulas e interagem mais (L9). O PIBID mostrou-me que é necessário abordar várias metodologias de ensino nas aulas de Matemática, para que elas não se tornem cansativas para os alunos (L21).

Quando desenvolvemos atividades diferenciadas, os alunos ficam mais motivados a aprender (L23).

Pude notar que, diante de aulas diferenciadas, as quais são preparadas anteriormente com um fim pedagógico, aumentou o incentivo dos alunos pela Matemática (L24).

O PIBID proporcionou a busca de criar estratégias para transmitir tais conteúdos de forma a maximizar o aprendizado por parte dos alunos (L26).

No PIBID nós podemos testar oficinas, metodologias e tendências, buscando encontrar um meio para ensinar os conteúdos matemáticos, levando o aluno a aprender (L46).

No PIBID conhecemos metodologias diferenciadas de ensino e colocamos em prática. Hoje, ao atuar em sala de aula, vejo o quanto isso é importante (L57).

Com o PIBID aprendi que a Matemática tradicional não é a única forma de ensinar matemática para os alunos. Aprendi que cada aluno tem sua maneira de aprender e preciso utilizar diversas maneiras de ensino (L76).

Na perspectiva dos coordenadores de área - formadores -, constatamos que eles reconhecem que o PIBID proporcionou oportunidades para os licenciandos em Matemática vivenciarem a maneira como desenvolver o ensino de Matemática por meio de diferentes abordagens metodológicas em sala de aula.

$\mathrm{Na}$ perspectiva dos supervisores - coformadores -, percebemos que as atividades do PIBID/Matemática proporcionaram aprendizagens tanto para os licenciandos em Matemática como para eles próprios, em relação ao planejamento e desenvolvimento de abordagens metodológicas diferenciadas para o ensino de Matemática, contribuindo, assim, para diversificar e melhorar a dinâmica das aulas de Matemática nas escolas públicas.

$\mathrm{Na}$ perspectiva dos licenciandos em Matemática, identificamos que, no PIBID, eles estavam sempre preocupados em elaborar atividades envolvendo diferentes abordagens metodológicas de ensino da Matemática, para diversificar a maneira de ensinar os conteúdos matemáticos aos alunos das escolas da Educação Básica.

$\mathrm{Na}$ nossa visão, a utilização de diferentes abordagens metodológicas no ensino de Matemática desenvolvidas pelos licenciandos diverge do formato das aulas tradicionais (práticas mecanicistas), promovendo, portanto, uma aprendizagem mais interativa e compartilhada. Assim sendo, podemos afirmar que, no PIBID/Matemática, os licenciandos possuíam a preocupação de ir além da simples transmissão dos conteúdos matemáticos, pois procuravam diversificar a dinâmica das aulas, o que demonstra um amadurecimento profissional.

Na perspectiva dos licenciandos participantes do PIBID/ Matemática, as sete principais abordagens metodológicas de ensino da Matemática desenvolvidas nas escolas parceiras estão contidas no gráfico da Figura 3.

Figura 3 - Gráfico das Metodologias de Ensino de Matemática desenvolvidas nas Escolas

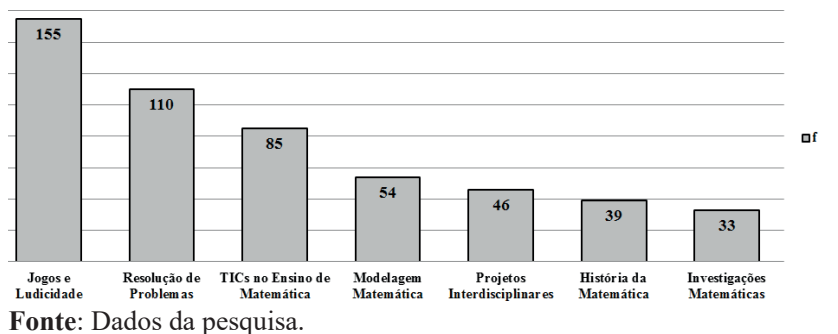

A partir da Figura 1, constatamos que as três metodologias de ensino da Matemática mais enfatizadas e desenvolvidas pelos licenciandos em Matemática participantes do PIBID nas escolas parceiras são: jogos e ludicidade, com 89\%; resolução de problemas, com $63,2 \%$, e tecnologias no ensino de Matemática, com 48,8\%. Como os jogos e a ludicidade se configuraram como a principal abordagem metodológica de ensino da Matemática desenvolvida pelos licenciandos nas escolas públicas, recorremos a diversos pesquisadores que enfatizam as contribuições dos jogos para o ensino de Matemática. 
Continuando, apresentamos no Quadro 4, as respostas dos participantes - 51 coordenadores de área, 40 supervisores e 174 licenciandos em Matemática - do PIBID/Matemática, a uma questão envolvendo a utilização de diferentes abordagens de ensino da Matemática nas escolas públicas parceiras.

Quadro 4 - Abordagens de ensino da Matemática nos encontros formativos

\begin{tabular}{|c|c|c|c|}
\hline $\begin{array}{c}\text { Durante os encontros coletivos de } \\
\text { formação aconteciam discussões } \\
\text { relacionadas às abordagens metodo- } \\
\text { lógicas de ensino de Matemática? }\end{array}$ & Sim & Não & Total \\
\hline Coordenadores de área & 50 & 01 & 51 \\
\hline Supervisores & 39 & 01 & 40 \\
\hline Licenciandos em Matemática & 170 & 04 & 174 \\
\hline
\end{tabular}

Fonte: Dados da pesquisa.

Com base no Quadro 4, identificamos que 98\% dos coordenadores de área, 97,7\% dos licenciandos em Matemática e $97,5 \%$ dos supervisores afirmaram que, durante os encontros de formação coletivos, aconteciam discussões relacionadas às diferentes abordagens metodológicas de ensino de Matemática. Assim sendo, podemos afirmar que os participantes do PIBID/Matemática tiveram oportunidades de utilizar diferentes metodologias de ensino de Matemática em salas de aula das escolas parceiras.

A esse respeito, Oliveira (2014, p.108) afirma que o PIBID proporciona aos licenciandos oportunidades de vivenciar experiências com diferentes abordagens metodológicas, pois assim eles podem "adquirir maior segurança para sua atuação, tendo a possibilidade de preparar, aplicar e refletir sobre uma atividade, o que proporciona um amadurecimento da prática e amplia a visão sobre o que é ensinar e como ensinar".

Para Shulman (1986), o conhecimento pedagógico do conteúdo é o que se destaca, por seu papel de integrar os demais conhecimentos, visando tornar os conhecimentos do conteúdo mais acessíveis aos alunos. Complementando essas ideias, o autor afirma que:

Dentro da categoria do conhecimento pedagógico do conteúdo estão incluídas, além dos tópicos mais regularmente ensinados sobre um assunto, as formas mais úteis de representação dessas idéias, as analogias mais poderosas, ilustrações, exemplos, explicações e demonstrações - em uma palavra, as formas de representar e formular o assunto para que se torne mais compreensível para os outros (Shulman, 1986, p.9).

Complementando, Shulman (2005) afirma que é o conhecimento pedagógico do conteúdo que possibilita distinguir e diferenciar um bom matemático de um bom professor de Matemática, uma vez que este último possui como característica principal articular seus conhecimentos dos conteúdos matemáticos em diferentes abordagens metodológicas para ensiná-los aos seus alunos, favorecendo assim a aprendizagem destes.

Corroborando os autores mencionados, na presente pesquisa consideramos as diferentes abordagens metodológicas de ensino de Matemática como sendo fundamentais para os licenciandos em Matemática adquirirem o conhecimento pedagógico do conteúdo.

Com base no movimento dialógico realizado, podemos afirmar que as diferentes abordagens metodológicas de ensino da Matemática apresentam a necessidade de rompimento do tradicionalismo pedagógico predominante nas aulas de Matemática. Assim, por meio da participação no PIBID, acreditamos que os futuros professores de Matemática tiveram oportunidades de adquirir conhecimentos pedagógicos do conteúdo para romper com o tradicionalismo pedagógico predominante nas escolas da Educação Básica.

Um quarto conhecimento necessário à docênciaidentificado nos excertos dos participantes do PIBID/Matemática relacionase ao conhecimento curricular, concebido por Shulman (1986, p.10) como sendo "o conjunto de programas elaborados para o ensino de assuntos específicos e tópicos em um nível dado, a variedade de materiais instrucionais disponíveis relacionados a estes programas".

Reflexão crítica e ampla sobre documentos curriculares, materiais didáticos, etc. Possibilidade de criação e produção de diferentes materiais didáticos (F1).

Estudamos o currículo juntos e o material a ser encaminhado nas intervenções (F9).

A criação de material didático, planejamento de aulas e desenvolvimento de projetos pedagógicos que talvez não teria a oportunidade de desenvolver senão no PIBID (L18).

No PIBID tenho a oportunidade de desenvolver atividades pedagógicas diferentes no laboratório de Matemática (L44).

Conhecimentos matemáticos e toda sua documentação existente sobre a disciplina de Matemática (L63).

Conforme sinalizam esses excertos dos participantes do PIBID/Matemática, podemos afirmar que os licenciandos em Matemática tiveram oportunidades de planejar, construir e utilizar recursos e materiais didáticos diferenciados no desenvolvimento das intervenções pedagógicas nas escolas da Educação Básica.

Em relação ao conhecimento curricular dos conteúdos, Paiva (2002, p. 97) declara que os professores precisam refletir a respeito dos conteúdos que serão ensinados em sala de aula, pois "se faz necessário, sobretudo, um conhecimento epistemológico do assunto, a ser ensinado, que garanta ao professor uma autonomia intelectual que o torne capaz de construir seu próprio currículo".

O conhecimento curricular do conteúdo também envolve a capacidade de o futuro professor planejar, desenvolver e reestruturar práticas pedagógicas, direcionando os conteúdos das atividades conforme os níveis escolares. Assim sendo, entendemos que os momentos de planejamento, elaboração e desenvolvimento das intervenções são fundamentais para os licenciandos em Matemática adquirirem o conhecimento curricular dos conteúdos, pois, para eles elaborarem uma atividade de ensino envolvendo um determinado conteúdo, antes precisam se atentar para os programas escolares, para os livros didáticos e para os níveis (matriz curricular) de ensino da Educação Básica.

Um quinto conhecimento necessário à docência 
identificado nos excertos dos participantes do PIBID/ Matemática relaciona-se ao conhecimento dos alunos e os seus processos de aprendizagem. Ao analisar as proposições de Shulman, \& Mizukami (2004, p.5) afirma que o conhecimento dos alunos envolve "as características dos alunos, processos cognitivos e desenvolvimentais de como os alunos aprendem".

O PIBID contribui para minha visão quanto à escola, sala de aula, postura de professor e preocupação com o aprendizado do aluno (L16).

No PIBID aprendemos como lidar com alunos difíceis e alunos com diferentes idades (L49).

É uma ótima oportunidade para perceber as necessidades individuais de cada aluno, pois são vários tipos de alunos, cada um com suas expectativas e necessidades (L70).

Com base nesses excertos, podemos inferir que a vivência dos licenciandos em Matemática na realidade das escolas públicas é uma contribuição proporcionada pelo PIBID, pois, ao vivenciarem a rotina escolar, eles possuem oportunidades de conhecer os alunos e os seus processos de aprendizagem. Assim sendo, o contato com o ambiente escolar possibilita aos futuros professores de Matemática uma visão real dos conhecimentos dos alunos e da maneira como eles aprendem, por meio da observação e realização das intervenções didáticas em sala de aula com os alunos da Educação Básica, sempre com o auxílio dos professores supervisores.

Ressaltamos ainda que os professores supervisores contribuíram com a formação dos futuros professores de Matemática, proporcionando-lhes orientações e recomendações para a atuação deles durante as ações do PIBID/Matemática em sala de aula e também para a formação profissional, como consta nos excertos a seguir:

Nunca gritar numa sala de aula, fazer com que o educando tenha prazer de estar na aula de Matemática, sem medos, com vontade de aprender e participar (S3).

Procure primeiro conquistar o seu aluno, tenha uma relação horizontal (S11).

Orientei eles em como tratar o aluno, o que falar e o que não falar e como fazê-lo (S21).

Eu sempre deixava claro para eles sempre planejarem (bem) as aulas, respeitando a individualidade de cada turma. Ter sempre plano A, B e C. Ser gentil, educado, amigo e respeitar o aluno como pessoa. Trazer a realidade do aluno para a sala de aula. Não deixar o aluno ir com dúvidas para casa. Nunca "bater de frente" com o aluno (S22).

De acordo com esses excertos dos supervisores, podemos destacar que as orientações dos supervisores para os licenciandos em Matemática participantes do PIBID estavam relacionadas à postura profissional e como se comportar à frente de uma sala de aula, linguagem e relacionamento com os alunos.

Um sexto conhecimento necessário à docência identificado nos excertos dos participantes do PIBID/Matemática relaciona-se ao conhecimento dos contextos educativos, o qual é definido por Shulman $(2005$, p.11) como sendo o conhecimento que abarca "desde o funcionamento do grupo, classe a gestão e financiamento dos distritos escolares até o caráter das comunidades e culturas".
O contato com a rotina das escolas públicas já fornece aos futuros professores aparatos do ambiente do qual eles farão parte futuramente (S5).

Ter contato com a escola pública e conhecer a realidade onde a escola está inserida é uma excelente aprendizagem aos acadêmicos junto à realidade da escola pública (S22).

O contato com o ambiente escolar, que ao meu ver a graduação deixa a desejar, é suprido de forma espetacular pelo PIBID (L11).

Essa vivência direta desde o planejamento de atividades até sua aplicação com os alunos, o que nos dá a oportunidade de conhecer o meio no qual estaremos sendo inseridos (L70).

Com base nesses excertos dos participantes, podemos inferir que o PIBID proporcionou, para os licenciandos em Matemática, conhecimentos relacionados aos contextos escolares, por meio do contato, inserção e vivência no ambiente escolar em seus processos de formação inicial. Para nós, esse aspecto, de inserir na realidade escolar, contribuiu para os licenciandos em Matemática vivenciarem a realidade escolar e profissional, para adquirir diversos conhecimentos relacionados à prática docente.

A esse respeito, Nóvoa (2009, p. 184) afirma que a escola é o melhor lugar para aprender a lecionar, pois proporciona oportunidades para a produção de práticas educativas eficazes, por meio de reflexões da experiência pessoal partilhada entre os colegas. O referido autor declara que a escola se constitui como "um lugar da formação dos professores, como o espaço da análise partilhada das práticas, enquanto rotina sistemática de acompanhamento, de supervisão e de reflexão sobre o trabalho docente".

Complementando essas ideias, Garcês, \& Garcês (2010, p.39) enfatizam que a escola pública é o ambiente ideal para a iniciação à docência, pois, nesse ambiente, o licenciando encontrará "problemas, falhas, dificuldades e obstáculos que o ajudarão em sua formação docente, formando, assim, um licenciado mais capacitado para posterior atuação, melhorando assim a Educação Básica no país”.

A presença dos licenciandos em Matemática no contexto escolar, vivenciando experiências formativas no dia a dia dos professores e interagindo com os alunos das escolas, tem sido fundamental para seus processos de aprendizagem da docência. Dessa maneira, defendemos a presença dos licenciandos no contexto escolar desde os anos iniciais da licenciatura em Matemática, pois as experiências no espaço escolar são fundamentais para a formação de professores, pois é na escola que o futuro professor adquire conhecimentos da sua futura atuação profissional.

Constatamos ainda que a participação dos licenciandos em Matemática nas atividades do PIBID/Matemática contribuiu para ampliar a visão a respeito da realidade escolar no contexto escolar, como consta no Quadro 5, que mostra as respostas deles a uma questão em relação ao ambiente escolar. 
Quadro 5 - Participação dos licenciandos em Matemática no contexto escolar

\begin{tabular}{|c|c|c|}
\hline $\begin{array}{l}\text { Sua participação no PIBID/Matemática } \\
\text { contribuiu para ampliar a sua visão a respeito } \\
\text { da realidade profissional no contexto escolar? }\end{array}$ & $\mathrm{F}$ & $\mathbf{( \% )}$ \\
\hline Sim & 172 & $99 \%$ \\
\hline Não & 02 & $01 \%$ \\
\hline
\end{tabular}

Fonte: Dados da pesquisa.

Com base nesses dados, podemos inferir que o convívio dos licenciandos no contexto escolar, amparado por professores das escolas e das universidades aptos a discutir e problematizar certas situações vivenciadas na escola, acaba por propiciar oportunidades de os futuros professores conhecerem a realidade das escolas públicas. Dessa maneira, entendemos que um aspecto central no processo da formação inicial dos futuros professores é a necessidade de aproximação entre os contextos de formação inicial e os contextos de atuação profissional do professor na Educação Básica.

Sobre isso, Libâneo (2001, p.20) retrata os espaços escolares como ambientes de aprendizagem do professor, pois "a escola é vista como um ambiente educativo, como espaço de formação". Para o autor, "é na escola que o professor coloca em prática suas convicções, seu conhecimento da realidade, suas competências pessoais e profissionais" (Libâneo, 2001, p.24).

Compactuamos com essa proposição, pois a experiência dos futuros professores no ambiente escolar possibilita uma ideia real do trabalho de um professor e da realidade profissional, que envolve a compreensão das atividades e da carreira docente. Assim sendo, podemos enfatizar que o PIBID/Matemática tem proporcionado aos licenciandos entender sobre a dinâmica das escolas da Educação Básica, pois podem participar da elaboração de planejamentos, reuniões de conselho escolar, de reuniões de pais e mestres, da elaboração e desenvolvimento de aulas de reforço.

Além disso, apresentamos, no Quadro 6, as respostas dos 174 licenciandos em Matemática a uma questão do Questionário.

Quadro 6 - Desenvolvimento de aulas de reforço no contexto escolar

\begin{tabular}{|c|c|c|}
\hline $\begin{array}{l}\text { Ministrou aulas de reforço e acompanhamen- } \\
\text { to na escola parceira em períodos extras? }\end{array}$ & F & (\%) \\
\hline Sim & 134 & $74,7 \%$ \\
\hline Não & 40 & $25,3 \%$ \\
\hline
\end{tabular}

Fonte: Dados da pesquisa.

Esses dados nos mostram que os licenciandos em Matemática estão engajados no desenvolvimento das atividades do PIBID no contexto escolar, como consta neste excerto: "a escola aceita o programa porque acreditam que os bolsistas de iniciação à docência vão oferecer reforço aos alunos" (Licenciando 14).

Desse modo, os licenciandos, participantes do PIBID/ Matemática, têm colaborado com aulas de reforço e acompanhamento em períodos extras, para proporcionar aos alunos das escolas públicas oportunidades de avançar em suas aprendizagens.

Um sétimo conhecimento necessário à docência identificado nos excertos dos participantes do PIBID/ Matemática relaciona-se ao conhecimento dos objetivos, das finalidades e dos valores educativos. Corroborando essas ideias, apresentamos alguns excertos a seguir:

Para mim, o PIBID contribui grandemente para minha visão quanto à escola, sala de aula, postura de professor e preocupação com o aprendizado do aluno (L16).

O PIBID/Matemática mostrou-me que ser professor não é fácil, e sim precisa de muita dedicação para termos sucesso em sala de aula e com os alunos (L21).

Por meio do PIBID eu pude estar aprendendo e vendo o que é ser professor. Ter a postura na frente da turma e saber repassar o conteúdo (L41).

Ter cuidado com os alunos, postura em sala de aula e suas falas (S12).

Postura profissional; ética docente; Planejamento de aula; organização de tempo; intervenção pedagógica; preocupação com a aprendizagem do aluno; responsabilidade social com o ser humano em formação (S13).

Amaneira de como lidar, a postura, a ética, o comprometimento podem ser "imitados" de certa maneira. Se mostrar como um profissional ético (ou ao menos, tentar) já é uma forma de ensinar (S16).

De acordo com esses excertos dos participantes, percebemos que o PIBID proporcionou aos licenciandos em Matemática conhecimentos importantes para a atuação de um professor, relacionados à postura e compromisso profissional, além da responsabilidade e da ética profissional no desenvolvimento de suas ações docentes. Ressaltamos a importância das orientações dos formadores das universidades e coformadores das escolas, em relação aos diversos aspectos profissionais que a docência requer, os quais serão importantes para a futura atuação como professores de Matemática.

Para Contreras (2002, p. 78), a função dos professores não é somente o ensino dos conteúdos pelos conteúdos, mas sim a busca pela formação de indivíduos, pois "o compromisso profissional de um professor reside em modificar a situação em que se encontra, superando as contradições ou dilemas, ou encontrar argumentos ou razões para justificar sua situação".

A esse respeito, Leite (2011, p.20) afirma que "o docente precisa ter preparo para compreender os desafios inerentes ao processo de ensino-aprendizagem e assegurar-se da importância dos princípios em relação ao caráter ético de sua atividade".

Nessa perspectiva, Lodi (2010, p.79) enfatiza que uma educação em sintonia com a prática da ética pressupõe dos professores a busca por "apreender conceitos, técnicas, saberes, que sejam significativos, transformadores, construtores de pessoas, através de procedimentos relacionais, desafiadores, geradores de seres humanos e não apenas de pessoas". A referida pesquisadora complementa afirmando que "de nada adianta acumular saberes e informações, se estes não nos tornam melhores e mais capazes de agir e melhorar o meio em que convivemos e em que atuamos" (Lodi, 2010, p.79). 
Com relação a isso, entendemos que os aspectos éticos devem ser considerados como compromissos dos professores na sua prática pedagógica, pois a ética docente está relacionada ao agir dos professores, a suas atitudes, à maneira como eles planejam suas aulas e organizam os conteúdos, envolvendo também a maneira como eles se relacionam com seus alunos.

Com base nos dados e referenciais teóricos explicitados, podemos afirmar que, no PIBID, os licenciandos em Matemática tiveram oportunidades de aprender aspectos relacionados à ética docente, postura, compromisso, responsabilidade e atuação profissional, que são aspectos fundamentais do conhecimento dos valores educativos da carreira docente.

Apesar de Shulman (2005) explicitar sete conhecimentos necessários à docência, identificamos um oitavo conhecimento necessário à docência, que envolve os conhecimentos políticos da profissão, como consta no excerto do coordenador de área a seguir:

A escola deve pensar no bolsista como integrante do corpo docente da escola, comunicando-o e requerendo sempre que possível a participação deles em eventos, reuniões administrativas e pedagógicas, assembleias, reuniões do conselho deliberativo, apresentação dos resultados obtidos através do PIBID para o corpo docente em formações continuadas e em todas outras atividades desenvolvidas pela escola e também pelo sindicato, é importante que os bolsistas reconheçam que as atividades docentes vão além da sala de aula (F7).

No Quadro 7, as respostas dos 174 licenciandos em Matemática a uma questão sobre o conhecimento político da profissão.

Quadro 7 - Conhecimento Político da Profissão pelos licenciandos em Matemática

\begin{tabular}{|c|c|c|}
\hline $\begin{array}{l}\text { Conheceu todas as dimensões do trabalho } \\
\text { docente (gestão da escola, movimento } \\
\text { sindical, etc.)? }\end{array}$ & F & (\%) \\
\hline Sim & 92 & $53 \%$ \\
\hline Não & 82 & $47 \%$ \\
\hline
\end{tabular}

Fonte: Dados da pesquisa.

Esses dados nos evidenciam que os licenciandos em Matemática tiveram oportunidades de conhecer dimensões importantes do trabalho docente, como gestão da escola e movimento sindical. No entanto, $47 \%$ dos licenciandos em Matemática afirmaram não terem tido esta oportunidade de conhecer aspectos importantes da profissionalidade docente.

Desta maneira, entendemos que o conhecimento político da profissão é fundamental para os futuros professores enfrentarem os diversos desafios que a profissão exige, objetivando recuperar um pouco essa característica de profissionalização do professor, de começar a ser visto e respeitado como profissional pelos gestores educacionais.

No processo de formação de professores, acreditamos ser preciso criar um compromisso político com a profissão, que está imbuído de responsabilidade e comprometimento com o coletivo - preocupação com a coletividade e com os companheiros de profissão -, nas discussões pela profissionalização da carreira docente e na luta para combater e resistir à proletarização imposta pelos gestores educacionais.

A esse respeito, Nóvoa (1995, p.23) faz uma distinção entre a profissionalização e a proletarização, ao afirmar que "profissionalização é um processo através do qual os trabalhadores melhoram o seu estatuto, elevam os seus rendimentos e aumentam o seu poder/autonomia. Ao invés, a proletarização provoca uma degradação do estatuto, dos rendimentos e do poder/autonomia".

$\mathrm{Na}$ nossa visão, todos os profissionais da Educação possuem responsabilidades no processo de reverter a tendência atual de queda das licenciaturas e de valorização da docência. Assim sendo, acreditamos que, se os profissionais da Educação atuarem coletivamente, poderão constituir-se futuramente como uma carreira de Estado desejada e valorizada.

\section{Conclusão}

A partir do movimento dialógico realizado, podemos afirmar que a participação nas atividades do PIBID/ Matemática proporcionou oportunidades para os licenciandos em Matemática adquirirem os sete conhecimentos necessários para a docência: 1) conhecimento do conteúdo; 2) conhecimento pedagógico; 3 ) conhecimento pedagógico do conteúdo; 4) conhecimento do currículo; 5) conhecimento dos alunos e dos seus processos de aprendizagem; 6) conhecimento dos contextos educativos; 7) conhecimento dos objetivos, das finalidades e dos valores educativos - conforme explicitado por Shulman (2005).

Além desses, na presente pesquisa, elencamos os conhecimentos políticos da profissão docente como um oitavo conhecimento necessário à docência, pois constatamos que, no PIBID, aproximadamente metade dos licenciandos em Matemática adquiriu os conhecimentos políticos da profissão, tendo assim oportunidades de conhecerem uma importante dimensão do trabalho docente - o movimento sindical. $\mathrm{Na}$ nossa visão, os futuros professores de Matemática necessitam adentrar a carreira docente com um compromisso político com a profissão, o que envolve um senso de coletividade nas discussões e lutas pela valorização e profissionalização da carreira docente no Brasil.

Além dos conhecimentos necessários à docência aqui explicitados, destacamos que a aproximação das Universidades com as escolas nos processos formativos de professores de Matemática desde o início da formação inicial é um aspecto importante para os processos de aprendizagem dos diversos conhecimentos necessários à docência, pois o contato e engajamento dos futuros professores nas escolas contribuem para eles vivenciarem experiências envolvendo diferentes abordagens metodológicas de ensino da Matemática. Na nossa visão, o PIBID cumpre o movimento defendido por Nóvoa (2009), como princípio necessário para a formação de professores, na medida em que propõe situações em que as escolas da Educação Básica e seus professores possam se 
tornar colaboradores ativos nos processos da formação inicial de professores.

Elencamos ainda que o PIBID proporcionou uma formação diferenciada para os licenciandos em Matemática participantes em relação aos licenciandos que não são bolsistas do programa, porque proporciona uma antecipação da atuação docente nas escolas públicas. A esse respeito, Rodrigues (2016, p. 304) concluiu sua tese destacando que a formação obtida pelos licenciandos que participam como bolsistas do PIBID/Matemática se diferencia da dos demais licenciandos, "principalmente devido à manifestação de comportamentos que antes não eram tão percebidos, entre eles a participação mais significativa nas aulas visando à compreensão teórica dos problemas vivenciados e enfrentados na prática das escolas".

Para finalizar, afirmamos que o PIBID proporcionou aos licenciandos em Matemática oportunidades de adquirirem os conhecimentos necessários à docência de um professor de Matemática, além de provocar um movimento de repensar os processos de formação de professores vigentes nas licenciatura em Matemática no Brasil. Assim sendo, o PIBID apresenta possíveis caminhos para melhorar os processos formativos de professores no Brasil.

\section{Referências}

Bardin, L. (1977). Análise de conteúdo. Lisboa: Edições 70.

Capes. (2014). Relatório de Gestão (2009-2013). Brasília: Diretoria de Formação de Professores da Educação Básica DEB.

Contreras, J. (2002). Autonomia de Professores. São Paulo: Cortez.

D’ambrosio, U. (2004). Prefácio. In: M.C. Borba, \& J.L. Araújo, J. L. Pesquisa Qualitativa em Educação Matemática. Belo Horizonte: Autêntica.

Garcês, A. A. P.; Garcês, B. P. (2010). Utilização de programas institucionais para incentivo à docência: será esta a solução? Revista de Educação Popular, v. 8, n. 1, p. 35-40.

Leite, Y. U. F. (2011). O lugar das práticas pedagógicas na formação inicial de professores. São Paulo: Cultura Acadêmica.
Libâneo, J. C. (2001). Organização e Gestão da escola: teoria e prática. Goiânia: Alternativa.

Lins, R. C. (2000). Caminhos da Educação Matemática no Brasil. In: IV Encontro Brasileiro de Estudantes de Pós-Graduação em Educação Matemática, 2000, Rio Claro. Anais do IVEBRAPEM. Rio Claro: UNESP, v. único. p. 24-27.

Lodi, I. G. (2010). Ética: os desafios e contradições na profissão docente. Revista Evidência, v. 6, n. 6, p. 77-88.

Nóvoa, A. (2009). Para uma formação de professores construída dentro da profissão. In: Professores: Imagens do futuro presente. Educa, Lisboa - Portugal.

Nóvoa, A. (1995). Os professores e a sua formação. Lisboa: Publicações Dom Quixote; Instituto de Inovação Educacional.

Oliveira, M.C.S. (2014). Sentidos do Programa Institucional de Bolsa de Iniciação à Docência (PIBID) na formação de professores: Um estudo com egressos da Universidade Federal de São João Del-Rei. 121 f. Dissertação (Mestrado em Educação) - Universidade Federal de São João Del-Rei (UFSJ), São João Del-Rei.

Paiva, M.A.V. (2002). Saberes do professor de matemática: uma reflexão sobre Licenciatura. Educação Matemática em Revista, 99(11), 95-104.

Rodrigues, M. U. (2016). Potencialidades do PIBID como espaço formativo para professores de matemática no Brasil. $540 \mathrm{f}$. Tese (Doutorado m Educação Matemática) - Universidade Estadual Paulista, Instituto de Geociências e Ciências Exatas, Rio Claro/SP.

Sbem. (2003). Subsidios para a discussão de propostas para os cursos de licenciatura em matemática: uma contribuição da sociedade brasileira de educação matemática.

Silva, L.D. (2015). Conhecimentos presentes na disciplina de análise nos cursos de licenciatura em Matemática no Brasil. 2015. 235 f. Tese (Doutorado em Educação Matemática) Universidade Estadual Paulista, Instituto de Geociências e Ciências Exatas.

Shulman, L.S. (2005). Conocimiento y enseñanza: fundamentos de la nueva reforma. Profesorado. Revista de Currículum y Formación Del Profesorado Granada, 9(2), 1-30.

Shulman, L. S. (1987). Knowledge and teaching: Foundations of the new reform. Harvard Educational Review, 57(1).

Shulman, L. S. (1986) Those who understand: knowledge growth in teaching. Educational Researcher, 15(2), 4-14. 